\title{
HYPOTHESIS
}

\section{Epineurial Peptides: A Role in Neuropathic Pain?}

\author{
D.W. Zochodne
}

\begin{abstract}
Neuropathic pain is not well understood. Although central dorsal horn remodelling is likely important in maintaining chronic neuropathic pain, afferent activity from injured nerves or ganglia may initiate these changes. It is suggested, in this review that the peripheral nerve trunk is capable of sustaining a "flare" response as observed in injured skin and other tissues. The injury response may be associated with local vasodilatation, plasma extravasation and the generation of painful local afferent activity sustained by locally originating peptidergic fibers (nervi nervorum?). These fibers contain substance P, calcitonin gene-related peptide and other peptides that have been linked to nociceptive transmission. Manipulation of the local injury response of the nerve trunk by pharmacologic means may provide one strategy in the treatment of neuropathic pain.
\end{abstract}

RÉSUMÉ: Peptides de l'épinèvre: ont-ils un rôle dans la douleur neuropathique? La douleur neuropathique n'est pas bien comprise. Bien que le remodelage de la région centrale de la corne supérieure soit vraisemblablement important dans le maintien de la douleur chronique neuropathique, l'activité afférente provenent du nerf ou du ganglion endommagé peut initier ces changements. Dans cette revue, nous suggérons que le tronc nerveux périphérique est capable de soutenir une réponse amplifiée telle qu'observée dans la peau lésée et dans d'autres tissus. La réponsė au dommage peut être associée avec une vasodilatation locale, une extravasation plasmatique et la production d'activité afférente locale douloureuse soutenue par des fibres peptidergiques originant localement (nervi nervorum). Ces fibres contiennent de la substance $\mathrm{P}$, des peptides reliés génétiquement à la calcitonine et d'autres peptides qui ont été liés à la transmission nociceptive. La manipulation de la réponse à la lésion locale du tronc nerveux par des moyens pharmacologiques peut offrir une stratégie de traitement dans la douleur neuropathique.

Can. J. Neurol. Sci. 1993: 20:69-72

Chronic neuropathic pain is a common, but taxing disorder, not only to the patient, but also to the caregiver and to the investigator. The plasticity of sensory systems involved in nociceptive pathways is particularly evident in the dorsal horn of the spinal cord, perhaps the structure most responsible for the maintenance of the chronic pain state. ${ }^{1-4}$ Despite the impressive evidence favoring the crucial role of central sensory structures in the generation of chronic pain, dorsal horn synapses do not remodel of their own accord. Afferent activity from neuromas, injured axons and the dorsal root ganglia are the presumed initiators of central adaptations. ${ }^{3,5-9}$ There may also be "silent nociceptors" in the peripheral nerve trunk itself that become active during injury or inflammation. ${ }^{10}$ How afferent activity from neuropathy generates pain and exactly how the afferent activity arises, however, is not fully understood. Clinical observations add further puzzles. For example, why is it that compression of the median nerve at the carpal tunnel, with an identical degree of sensory conduction slowing, may be exquisitely painful in one patient, but painless or "asymptomatic" in another. There would appear to be very little correlation between endoneurial events that influence conduction velocity and conduction block and those that act as local pain generators.

Asbury and Fields $"$ discussed the origin of neuropathic pain and raised the possibility that sensory fibers innervating the nerve trunk connective tissue (nervi nervorum) might contribute to nerve trunk pain. ${ }^{12-14}$ Examples of nerve trunk pain may be the deep aching discomfort associated with brachial neuritis or spinal nerve root irritation. A second type of pain may arise directly from injured axons, with hyperaesthesia in the distribution of the injured nerve, as in some "small fiber" polyneuropathies.

In skin, cornea and other tissues, neurogenic inflammation plays an important role in the injury response and in the production of hyperalgesia. ${ }^{15-17}$ Several mediators have been implicated including the tachykinins substance P (SP), and Neurokinin A (NKA), calcitonin gene-related peptide (CGRP), histamine from mast cells, circulating bradykinin, ATP and others. ${ }^{16 \cdot 21}$ Histamine may depolarize afferent nerve fibers as part of an

From the Department of Clinical Neurosciences, University of Calgary, Calgary

Received July 28, 1992. Accepted September 30, 1992

Reprint requests to: Dr. D. Zochodne, Room 182-A, Heritage Medical Research Bldg., 3330 Hospital Drive N.W., Calgary, Alberta, Canada T2N 4N I 
"axon reflex", or "axon response" enlarging the nocifensor territory and increasing local peptide release. ${ }^{16.21} \mathrm{SP}$, in turn, induces release of histamine from mast cells, increasing the neurogenic inflammatory cycle. SP also participates in vasodilation, plasma extravasation and immune modulation. ${ }^{22}$ CGRP is a particularly potent vasodilator, ${ }^{23}$ and NKA may contribute toward hyperalgesia. ${ }^{24}$ SP and CGRP, modulated by endogenous opioids, may act as synergistic neurotransmitters at the central process of primary afferent fibers as they synapse in the dorsal horn of the spinal cord..$^{25-27}$ It is appealing to suggest that a similar cooperative interaction could occur in the parallel peripheral process of the primary afferent fiber.

If the nervi nervorum hypothesis of Asbury and Fields ${ }^{11}$ is correct, pain generation in damaged nerve trunk connective tissue would require participation of nociceptive sensory fibers and involvement of one or more pain mediators. Finally, it would be helpful to identify adrenergic fibers that could account for "sympathetically maintained" neuropathic pain. All of the requirements for "neurogenic inflammation" and the nervi nervorum hypothesis exist in the peripheral nerve trunk. Vasa nervorum, particularly in the epineurium are innervated by peptidergic fibers with terminals containing SP, CGRP, and others. ${ }^{13,28}$ The peptidergic fibers probably arise from the parent nerve trunk to innervate its own vasa nervorum and there is evidence of "tonic" peptide release, implying a role in local vasoregulation. ${ }^{28}$ Mast cells are present in both the epineurium and endoneurium. ${ }^{29}$ The epineurial plexus is also innervated by adrenergic fibers and there is evidence that these fibers have tonic activity. ${ }^{30-33}$

From work in our laboratory, we have postulated the existence of a "peripheral nerve trunk flare" akin to peptide-mediated flares in other tissues, that could be active under conditions of injury. The nerve trunk flare shares many features with that of skin, for example. It is probably important in the nerve trunk hyperemia induced by remote whole nerve trunk stimulation (akin to the skin hyperemia that occurs following antidromic stimulation of its cutaneous nerve supply). ${ }^{34}$ It may be modeled by the acute effects of local capsaicin, that depolarizes nerve terminals through a unique receptor complex and results in acute release of SP, CGRP and probably other neuropeptides. ${ }^{35}$ The local flare induced by epineurial capsaicin is immediate, intense and persistent. ${ }^{28}$ Moreover, the flare may be prevented on interrupted by antagonists of SP or CGRP, prior capsaicin "desensitization", removal of the epineurial plexus, or administration of systemic antihistamines or cromolyn, acting as a mast cell "stabilizer". ${ }^{28,36}$ The sensitivity of the capsaicin flare to pharmacological inhibition is interesting and might be explained by a serial multistep process involving several mediators. How these mediators interact, however, is unknown. A hypothesized scheme is illustrated in Figure 1. Capsaicin nerve trunk hyperemia is locally generated, not requiring the partication of central sensory pathways, and is also inhibited by systemic opiate treatment. ${ }^{28.36}$

Of course, there are several critical unanswered questions in a hypothesized linkage between this flare response and the local generation of neuropathic pain. We have preliminary evidence that focal nerve trunk injury from local crush is associated with hyperemia, mediated at least in part by CGRP. ${ }^{37}$ It remains to be established whether these peptidergic vascular events arising from sensory fibers also correlate with ascending afferent impulses that are significant enough to remodel and dorsal horn. It would also be interesting to determine if there are peptide

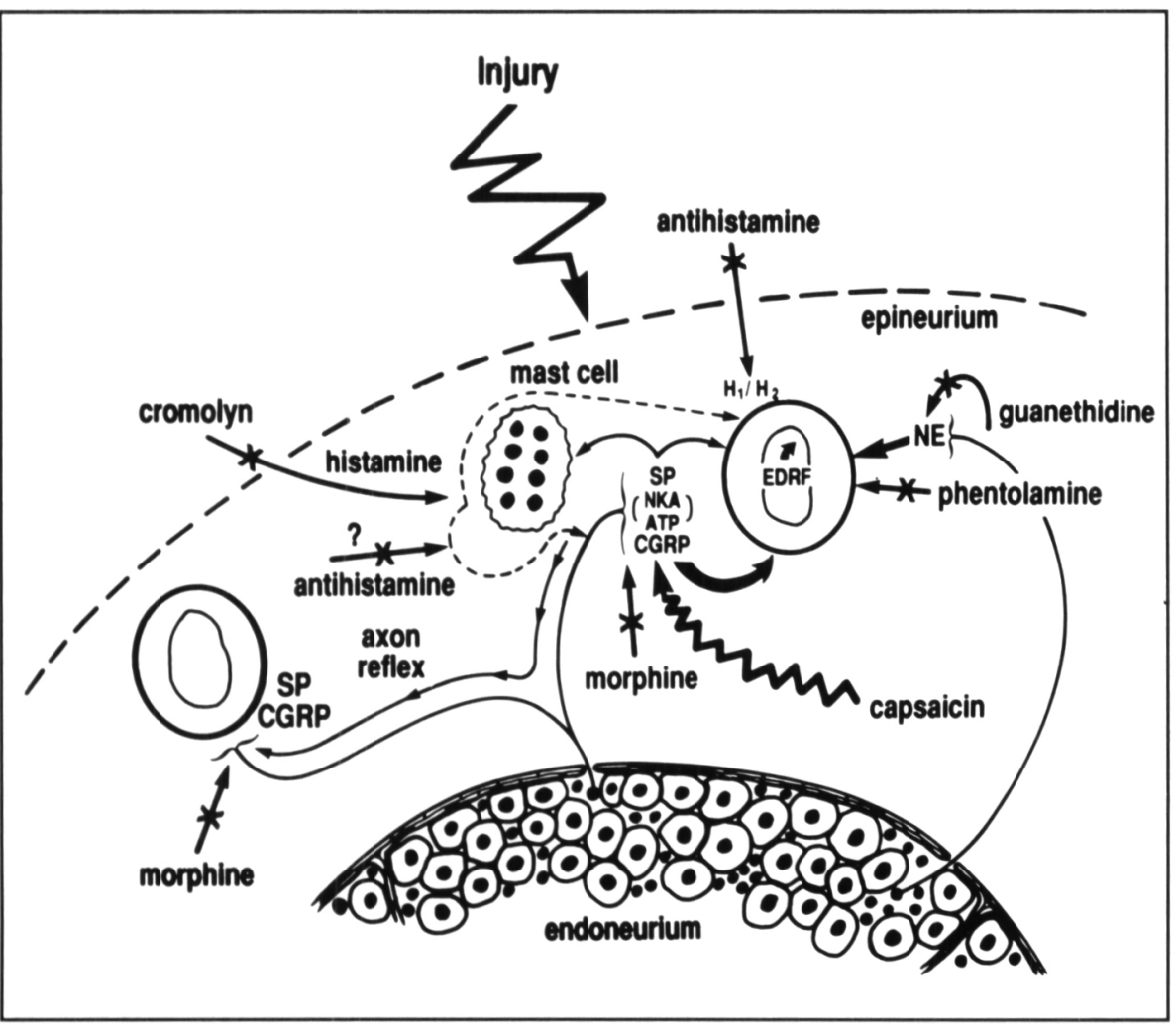

Figure 1-Proposed mechanism of the flare response of peripheral nerve "nervi nervorum". NE (noradrenergic) fibers are vasoconstrictive inhibited by phentolamine or depleted of NE by chronic guanethidine treatment. Peptidergic fibers contain $S P$ (substance $P$ ) and CGRP (calcitonin gene-related peptide) that dilate epineurial vessels, likely by an endothelial-dependent mechanism (through EDRF, endothelium-derived relaxing factor, now known to be nitric oxide). CGRP is a more potent vasodilator than $S P$. but peptidergic fibers also contain other substances (NKA, ?ATP). $S P$ degranulates mast cells (prevented by cromolyn) to release histamine (blocked by $\mathrm{Hl}$ and $\mathrm{H} 2$ histamine receptor antagomists) that vasodilates directly and depolarizes peptidergic fibers to enhance the inflamed territory by an axon reflex. Morphine probably inhibits SP release. We have postulated that both capsaicin and nerve injury are capable of producing the nerve trunk flare. 
receptors on perivascular fibers, injured axons or regenerating fibers to further generate nociceptive volleys.

Of related interest are recent clinical reports of the efficacy of local capsaicin cream in the treatment of some neuropathic disorders associated with hyperesthesia and allodynia. ${ }^{38-40}$ The mechanism of topical capsaicin action in these disorders is uncertain. Capsaicin causes conduction block of nociceptive afferents, interrupts axonal transport of SP and may deplete local nociceptive terminals of their peptide contents. ${ }^{35.41}$ Yet another mechanism may underlie the phenomenon of capsaicin desensitization. ${ }^{35.42}$ There is little evidence that capsaicin cream benefits patients by a neurotoxic action on dorsal root ganglia, as occurs in animals following systemic treatment because sensory function is not permanently interrupted in animals or man by topical application..$^{43}$ Capsaicin usually takes repeated applications to be effective, arguing against conduction block or "counter-irritation" as a mechanism of action (although it could be in some patients). It is speculative, but interesting to suggest that the mechanism could be local depletion of SP and CGRP such that local hyperalgesia is not generated. In support of this idea is the observation that capsaicin cream blocks later attempts to evoke a skin flare response. This may be further evidence that there is a close relationship between peptide and histamine-related vascular events and pain generation. ${ }^{43}$ If topical capsaicin helps neuropathic pain by reducing peptide concentrations, how might this influence pain generation at a proximal site on the nerve trunk? It is possible that the lack of efficacy of capsaicin cream in some patients with neuropathic pain is a result of more proximal disease activity.

Perhaps most intriguing is the suggestion that opiate analgesics may have an antinociceptive action by interacting with local actions of peptides responsible for pain, vasodilation and plasma extravasation. This would be separate from its known central modulatory effects at the level of the spinal dorsal horn. ${ }^{44}$ It is conceivable that local opiate manipulation at sites of neuropathic injury, as recently demonstrated in postsurgical joints, might have a role in the treatment of neuropathic pain. ${ }^{45}$ The success of systemic opiates in the treatment of neuropathic pain has been debated, with some workers claiming that this form of pain is opiate unresponsive. ${ }^{46}$ Thus, whether modulation of neurogenic inflammation in the peripheral nerve trunk would be helpful in neuropathic pain is speculative. At the very least, our embarrassing lack of success in treating neuropathic pain should mandate a new approach to the problem, perhaps, through the local modulation of neuropeptides.

\section{ACKNOWLEDGEMENTS}

Mrs. Lisa Fregeau provided expert secretarial assistance. Funding support was provided by the Canadian Diabetes Association, the Muscular Dystrophy Association of Canada, the Medical Research Council of Canada and Queen's University (Botterell Fund, Principal's Development Fund Category B, Research Initiation Grant). Ethicon Corporation provided suture material. Dr. Zochodne has been a recipient of a Career Scientist Award from the Ontario Ministry of Health and is currently a Clinical Investigator of the Alberta Heritage Foundation for Medical Research.

\section{REFERENCES}

1. Baumann TK, Simone DA, Shain CN, LaMotte RH. Neurogenic hyperalgesia: the search for the primary cutaneous afferent fibers that contribute to capsaicin-induced pain and hyperalgesia. J Neurophysiol 1991; 66: 212-227.

2. Cook AJ, Woolf CJ. Wall PD, McMahon SB. Dynamic receptive field plasticity in rat spinal cord dorsal horn following C-primary afferent input. Nature 1987; 325: 151-153.

3. Wall $P D$, Devor $M$. The effect of peripheral nerve injury on dorsal rool potentials and on transmission of afferent signals into the spinal cord. Brain Res 1981; 209: 95-111.

4. Woolf CJ. Evidence for a central component of post-injury pain hypersensitivity. Nature 1983; 306: 686-688.

5. Nystrom B, Hagbarth K-E. Microelectrode recordings from transected nerves in amputees with phantom limb pain. Neurosci Lett 1981:27: 211-216.

6. Wall PD, Waxman S, Basbaum AI. Ongoing activity in peripheral nerve: injury discharge. Exp Neurol 1974: 45: 576-589.

7. Wall PD. Gutnick M. Properties of afferent nerve impulses originating from a neuroma. Nature 1974; $248: 740-743$.

8. Wall PD, Gutnick M. Ongoing activity in peripheral nerves: the physiology and pharmacology of impulses originating from a neuroma. Exp Neurol 1974; 43: 580-593.

9. Wall PD, Devor M. Sensory afferent impulses originate from dorsal root ganglia as well as from the periphery in nomal and nerve injured rats. Pain 1983; 17: 321-339.

10. McMahon S, Koltzenburg $M$. The changing role of primary afferent neurones in pain. Pain 1990; 43: 269-272.

11. Asbury AK, Fields HL. Pain due to peripheral nerve damage: an hypothesis. Neurology 1984: 34: 1587-1590.

12. Appenzeller O, Dhital KK, Cowen T, Burnstock G. The nerves 10 blood vessels supplying blood to nerves: the innervation of valsa nervorun. Brain Res 1984: 304: 383-386.

13. Dhital KK, Appenzeller O. Innervation of vasa nervorum. In: Burnstock G, Griffith SG, eds. Nonadrenergic Innervation of Blood Vessels. Volume II. Regional Innervation. Chapter 11. Boca Raton: CRC Press, 1988: 191-211.

14. Hromada J. On the nerve supply of the connective tissue of some peripheral nervous system components. Acta Anat 1963: 55: 343-351.

15. Holzer P. Local effector functions of capsaicin-sensitive sensory nerve endings: involvement of tachykinins, calcitonin gene-related peptide and other neuropeptides. Neuroscience 1988: 24: 739 . 768.

16. Lembeck F. Sir Thomas Lewis's nocifensor system, histamine and substance-P-containing primary afferent nerves. Trends Neurosci 1983; 6: 106-108.

17. Nakamura-Craig $M$, Smith TW. Substance $P$ and peripheral inflammatory hyperalgesia. Pain 1989: 38: $91-98$.

18. Beding-Barnekow B, Brodin E, Hakanson R. Substance P, neurokinin $A$ and neurokinin $B$ in the ocular response to injury in the rabbit. Br J Pharmacol 1988: 95: 259-267.

19. Gamse $R$, et al. Several mediators appear to interact in neurogenic inflammation. Acta Physiol Hung 1987; 69: 343-354.

20. Kiernan JA. A pharmacological and histological investigation of the involvement of mast cells in cutaneous axon reflex vasodilatation. Q J Exp Physiol 1975; 60: 123-130.

21. Rosenthal SR. Histamine as the chemical mediator for cutaneous pain. J Invest Dermatol 1977; 69: 98-105.

22. Weihe E, Nohr D, Muller S, Buchler M, Friess H, Zentel H-J. The tachykinin neuroimmune connection in inflammatory pain. $\mathrm{ln}$ : Leeman SE, Krause JE, Lembeck F, eds. Substance $P$ and related peptides: cellular and molecular physiology. Ann NY Acad Sci 1991; 632: 283-295.

23. Brain SD, Williams TJ, Tippins JR, Morris HR, MacIntyre I. Calcitonin gene related peptide is a potent vasodilator. Nature 1985; 313: 54-56.

24. Nakamura-Craig $M$, Gill BK. Effect of neurokinin A, substance $P$ and calcitonin gene related peptide in peripheral hyperalgesia in the rat paw. Neurosci Letl 1991: 124: 49-51.

25. Biella G, Panara C, Pecile A, Sotgiu ML. Facilitatory role of calcitonin gene-related peptide (CGRP) on excitation induced by substance $\mathrm{P}$ (SP) and noxious stimuli in rat spinal dorsal horn neurons. An iontophoretic study in vivo. Brain Res 1991; 559; 352-356. 
26. Dubner R, Rudda MA. Activity-dependent neuronal plasticity following tissue injury and inflammation. Trends Neurosci 1992; 15: 96-103.

27. Fields HL, Emson PC, Leigh BK, Gilbert RFT, Iversen LL. Multiple opiate receptor sites on primary afferent fibers. Nature 1980; 284: $351-353$

28. Zochodne DW, Ho LT. Influence of perivascular peptides on endoneurial blood flow and microvascular resistance in the sciatic nerve of the rat. J Physiol (London) 1991; 444: 615-630.

29. Vital C, Vallat J-M. Ultrastructural Study of the Human Diseased Peripheral Nerve. Second Edition, Elsevier: New York 1987.

30. Kihara M, Low PA. Regulation of rat nerve blood flow: role of epineurial alpha-receptors. J Physiol (London) 1990; 422: 145-152.

31. Rechthand E, Hervonen A, Sato S, Rapoport SI. Distribution of adrenergic innervation of blood vessels in peripheral nerve. Brain Res 1986; 374: 185-189.

32. Zochodne DW, Low PA. Adrenergic control of nerve blood flow. Exp Neurol 1990; 109: 300-307.

33. Zochodne DW, Huang Z, Ward KK, Low PA. Guanethidineinduced adrenergic sympathectomy augments and endoneurial perfusion and lowers endoneurial microvascular resistance. Brain Res 1990; 519: 112-117.

34. Zochodne DW. Ho LT. Stimulation-induced peripheral nerve hyperemia: mediation by fibers innervating vasa nervorum? Brain Res 1991; 546: 113-118.

35. Holzer P. Capsaicin: cellular targets, mechanisms of action, and selectivity for thin sensory neurons. Pharmacol Rev 1991; 43: 143-201.

36. Zochodne DW, Ho LT. Evidence that capsaicin hyperaemia of rat sciatic vasa nervorum is local, opiate-sensitive and involves mast cell degranulation. J Physiol (London) in press.
37. Zochodne DW, Ho LT. Hyperemia of injured peripheral nerve: sensitivity to CGRP antagonism. Brain Research, in press.

38. Bernstein JE, Bickers DR, Dahl MV, Roshal JY. Treatment of chronic postherpetic neuralgia with topical capsaicin. J Am Acad Derm 1987; 17: 93-96.

39. Capsaicin study group. Treatment of painful diabetic neuropathy with topical capsaicin. A multicenter, double-blind, vehicle-controlled study. Arch Intern Med 1991; 151: 2225-2229.

40. Dubner R. Topical capsaicin therapy for neuropathic pain. Pain 1991; 47: 247-248.

41. Buck SH, Burks TF. The neuropharmacology of capsaicin: review of some recent observations. Pharmacol Rev 1986; 38: 179-226.

42. Maggi CA. Capsaicin and primary afferent neurons: from basic science to human therapy? J Auton Nerv Syst 1991; 33: 1-14.

43. Simone DA, Ochoa J. Early and late effects of prolonged topical capsaicin on cutaneous sensibility and neurogenic vasodilatation in humans. Pain 1991; 47: 285-294.

44. Stevens CW, Lacey CB, Miller KE, Elde RP, Seybold VS. Biochemical characterization and regional quantification of $\mathrm{mu}$, delta, and kappa opioid binding sites in rat spinal cord. Brain Res 1991; 550: 77-85.

45. Stein C, Comisel K, Haimerl E, Yassouridis A, Lehrberger K, et al. Analgesic effect of intraarticular morphine after arthroscopic knee surgery. N Engl J Med 1991; 325: 1123-1126.

46. Portenoy RK, Foley KM, Inturrisi CE. The nature of opioid responsiveness and its implications for neuropathic pain: new hypotheses derived from studies of opioid infusions. Pain 1990; 43: 273286. 